\title{
Lactobacillus salivarius modulates cytokine induction and virulence factor gene expression in Helicobacter pylori
}

\begin{abstract}
Correspondence
Paul W. O'Toole
\end{abstract}

pwotoole@ucc.ie

Received 12 January 2009

Accepted 27 April 2009

\author{
Kieran A. Ryan, ${ }^{1,2}$ Ann M. O'Hara, ${ }^{1,3}$ Jan-Peter van Pijkeren, ${ }^{1,2}$ \\ François P. Douillard ${ }^{2}$ and Paul W. O'Toole ${ }^{1,2}$ \\ ${ }^{1}$ Alimentary Pharmabiotic Centre, University College Cork, Cork, Ireland \\ ${ }^{2}$ Department of Microbiology, University College Cork, Cork, Ireland \\ ${ }^{3}$ Department of Medicine, University College Cork, Cork, Ireland
}

\begin{abstract}
Human infection by the gastric pathogen Helicobacter pylori is characterized by a robust immune response which rarely prevents persistent $H$. pylori colonization. Emerging evidence suggests that lactobacilli may reduce $H$. pylori infection rates and associated inflammation. In this study, we measured the ability of two model strains of Lactobacillus salivarius (UCC118 and UCC119) to modulate gastric epithelial cell chemokine responses to $H$. pylori infection. Pre-treatment of AGS cells with either $L$. salivarius strain significantly decreased interleukin-8 (IL-8) production upon exposure to $H$. pylori, but not in cells stimulated with TNF- $\alpha$. The production of the chemokines CCL20 and IP-10 by AGS cells infected with $H$. pylori was also altered following pre-treatment with UCC118 and UCC119. We showed that a greater reduction in IL-8 production with UCC119 was due to the production of more acid by this strain. Furthermore, UV-killed cells of both lactobacillus strains were still able to reduce $H$. pylori-induced IL-8 in the absence of acid production, indicating the action of a second anti-inflammatory mechanism. This immunomodulatory activity was not dependent on adhesion to epithelial cells or bacteriocin production. Real-time RT-PCR analysis showed that expression of eight of twelve Cag pathogenicity island genes tested was downregulated by exposure to $L$. salivarius, but not by cells of four other lactobacillus species. CagA accumulated in $H$. pylori cells following exposure to $L$. salivarius presumably as a result of loss of functionality of the Cag secretion system. These data identified a new mechanism whereby some probiotic bacteria have a positive effect on $\mathrm{H}$. pyloriassociated inflammation without clearing the infection.
\end{abstract}

\section{INTRODUCTION}

Helicobacter pylori is a Gram-negative, spiral bacterium that colonizes the human gastric mucosa. Despite advances in our understanding of this pathogen and the development of treatment strategies, H. pylori remains a significant human health problem, and it still infects about $50 \%$ of the world's population (De Vries et al., 2008). $H$. pylori is a causative agent of a range of human diseases (Uemura et al., 2001). Although $H$. pylori elicits strong local and systemic immune responses in infected individuals, most hosts are unable to clear the infection and can remain infected for their lifetime (Robinson et al., 2007).

The chemokine interleukin-8 (IL-8) is an important mediator of the chronic inflammation that characterizes H. pylori infection. Cells of the gastric epithelium are

Abbreviations: CBA, cytometric bead array; IL-8, interleukin-8; PAI, pathogenicity island. induced to secrete IL-8 only following their injection with the CagA (cytotoxin associated gene $\mathrm{A}$ ) protein or peptidoglycan from $H$. pylori. CagA is translocated into host epithelial cells via a type IV secretion system, where it is phosphorylated by the host cells' own machinery (Higashi et al., 2002; Stein et al., 2000). Phosphorylated CagA induces changes in epithelial cell morphology which are thought to allow the bacterium to adhere at higher levels (Bourzac et al., 2007; Su et al., 2003).

In recent years, increases in the rates of $H$. pylori resistance to antibiotics have been widely reported (Graham \& Shiotani, 2008; Ryan et al., 2001; Vakil \& Megraud, 2007). Furthermore, due to the cost involved, antibiotic treatment for $H$. pylori infection is not freely available in developing countries where infection rates are highest (Magalhaes Queiroz \& Luzza, 2006). These factors, along with the many side effects commonly associated with antibiotic consumption, have prompted a search for alternative 
treatments or treatment adjuncts for $H$. pylori infection. A number of independent research groups have shown that probiotic organisms can have beneficial effects in the treatment of $H$. pylori infection (recently reviewed by Franceschi et al., 2007; Lesbros-Pantoflickova et al., 2007). It has also been shown that various probiotics can alter the immune response to Helicobacter infection by influencing cytokine release by the epithelium (Pena et al., 2005; Rokka et al., 2008; Sgouras et al., 2005). To date, studies on immune modulation by probiotic organisms have focused primarily on signal transduction events in the host and not on the bacterial factors which may facilitate these changes (O'Hara et al., 2006; Tamura et al., 2006; Zhou et al., 2008). As a result, the mechanisms whereby probiotic bacteria may effect such changes are very poorly understood.

In the present study, we investigated the ability of two wellcharacterized Lactobacillus salivarius strains to alter chemokine responses by gastric epithelial cells upon $H$. pylori infection and the mechanisms behind these phenomena. Strain UCC118 was originally isolated from the human ileal-caecal region and strain UCC119 was isolated from the chicken intestine (Ryan et al., 2008a). A number of differences have previously been noted between these strains, including the ability to inhibit growth of $H$. pylori (Ryan et al., 2008a).

\section{METHODS}

Cell lines and bacterial strains. AGS gastric epithelial cells were maintained in Ham's F-12 medium (Sigma) containing $10 \%$ heatinactivated fetal bovine serum (Sigma) at $37{ }^{\circ} \mathrm{C}$ in $5 \% \mathrm{CO}_{2}$.

H. pylori strain CCUG 17874 (Culture Collection, University of Göteborg, Sweden; identical to NCTC 11637, the type strain of $H$. pylori) was used in this study. This strain is a high-level IL-8 inducer strain (Brandt et al., 2005). Bacteria were routinely cultured on chocolate blood agar plates (Columbia agar base; Merck) supplemented with $10 \%(\mathrm{v} / \mathrm{v})$ heat-inactivated whole horse blood (Charles River Laboratories) for $48 \mathrm{~h}$ at $37{ }^{\circ} \mathrm{C}$ in an atmosphere containing $5 \% \mathrm{CO}_{2}$. Lactobacilli were cultured for $24 \mathrm{~h}$ in Man-Rogosa-Sharpe (MRS) broth (Oxoid) at $37{ }^{\circ} \mathrm{C}$ in $5 \% \mathrm{CO}_{2}$. L. salivarius UCC118 was isolated from the human ileal-caecal region (Dunne et al., 2001) and L. salivarius UCC119 was isolated from the chicken intestine (Ryan et al., 2008a). Lactobacillus reuteri DSM 2016 was obtained from the German Collection of Micro-organisms and Cell Cultures; Lactobacillus acidophilus ATCC 4356 was from the American Type Culture Collection; Lactobacillus plantarum NCIMB 8826 was from the National Collection of Industrial, Marine and Food Bacteria, UK; and Lactobacillus sakei LMG 2313 was from the Laboratory of Microbial Gene Technology, Norway (Corsetti et al., 2004).

To prepare cell envelope and cytoplasmic fractions of $L$. salivarius UCC118, cells were washed in PBS, and then resuspended in Ham's F12 medium. Cells were then lysed at 2000 p.s.i. using a French Press cell disrupter (Thermo Scientific). The cell lysate was centrifuged for $5 \mathrm{~min}$ at $12000 \mathrm{~g}$, after which the supernatant (cytoplasmic fraction) was removed. The pellet (cell envelope fraction) was resuspended in an identical volume of Ham's F-12 medium.

Co-culture assay. AGS cells were seeded into a 24 -well plate at a concentration of $1 \times 10^{5}$ per well or into a 6-well plate at a concentration of $1 \times 10^{6}$ per well and grown overnight. An overnight culture of lactobacillus was washed twice in sterile PBS and resuspended in Ham's F-12 medium. AGS cell culture medium was changed to serum-free Ham's F-12 and the lactobacillus cells were added at the required concentration. AGS cells and lactobacilli were cultured together for $2 \mathrm{~h}$ before the addition of $H$. pylori. H. pylori cells were removed from a $48 \mathrm{~h}$ chocolate blood agar plate into $1 \mathrm{ml}$ BHI broth. Cells were washed twice in sterile PBS, resuspended in Ham's F-12 and added to the co-culture plate at the required concentration. After $4 \mathrm{~h}$ further incubation, the supernatants were collected.

To investigate the specificity of anti-inflammatory effects, $5 \mathrm{ng}$ tumour necrosis factor alpha (TNF- $\alpha) \mathrm{ml}^{-1}$ (R\&D Systems) was used in the assay instead of $H$. pylori to induce IL-8 secretion.

IL-8/CCL20 ELISA. Cell supernatants were collected from $H$. pylorilactobacillus co-cultures and stored at $-20{ }^{\circ} \mathrm{C}$ until processing. Following thawing, supernatants were tested for IL-8 protein using the DuoSet kit (R\&D Systems) or for CCL20 using the Quantikine kit (R\&D Systems), both according to the manufacturer's instructions.

Cytokine cytometric bead array (CBA) assay. The levels of CCL5 (RANTES), CXCL9 (monokine induced by interferon- $\gamma$ ), CCL2 (monocyte chemoattractant protein-1) and CXCL10 in cell-culture supernatants were measured simultaneously by CBA using the human chemokine CBA kit I (BD Biosciences). In CBA, bead populations with distinct fluorescence intensities and coated with capturing antibodies specific for each chemokine were incubated with cellculture supernatant $(10 \mu \mathrm{l})$ according to the manufacturer's instructions. Following incubation with a mixture of phycoerythrinconjugated antibodies to the test chemokines, the samples were analysed using a four-colour FACSCalibur flow cytometer (BD Biosciences). The concentration of each chemokine in the culture supernatants was interpolated from a standard curve, which was generated with each recombinant chemokine, using FCAP Array software (BD Biosciences). The assay sensitivities of CCL5, CXCL9, CCL2 or CXCL10 were 1.0, 2.5, 2.7 or $2.8 \mathrm{pg} \mathrm{ml}^{-1}$, respectively.

Real-time PCR. Bacteria were collected from $H$. pylori-lactobacillus co-cultures by centrifugation for $15 \mathrm{~s}$, and then placed in RNA Bacteria Protect Reagent (Qiagen). Total RNA was extracted using the RNeasy Mini kit (Qiagen) according to the manufacturer's protocol for Gram-negative bacteria, and then treated for $2 \mathrm{~h}$ with TURBO DNA-free DNase (Ambion). RNA yield was estimated by Nanodrop (Thermo Scientific). A minimum of $0.2 \mu \mathrm{g}$ RNA was reversetranscribed using $20 \mathrm{ng}$ random primer and the Improm-II reverse transcriptase enzyme (both from Promega) as per the manufacturer's protocol. Real-time PCR primers for 10 Cag pathogenicity island (PAI) genes and vacA were designed using the Primer3 online software package (http://frodo.wi.mit.edu/cgi-bin/primer3/primer3 www.cgi). Primer sequences are listed in Table 1. qRT-PCR was performed using an AB7000 thermocycler (Applied Biosystems). Each $12.5 \mu \mathrm{l}$ reaction contained $50 \mathrm{nM}$ of each primer, $6.25 \mu \mathrm{l} 2 \times$ Master Mix and 1/60000 SYBR Green I (both from Biogene). Individual amplification reactions were first established and optimized for single-band specificity, verified by running pilot reaction products on gel, and monitoring of dissociation curves of all subsequent test reactions. Reactions were performed in triplicate and crossing threshold (ct) values were averaged. Fold change in expression was calculated according to the standard formula $2^{(E n-R n)-(E t-R t)}$, where $E n$ is the ct of the experimental gene in the normal (H. pylori alone) sample, $R n$ is the ct of the reference gene in the normal sample, Et is the ct of the experimental gene in the treated ( $H$. pylori and lactobacillus) sample and $R t$ is the ct of the reference gene in the treated sample. qRT-PCRs were repeated on three different biological replicates and fold expression changes were averaged. 
Table 1. PCR primers used in this study

\begin{tabular}{|c|c|c|}
\hline Gene (TIGR designation) & Forward primer $\left(5^{\prime} \rightarrow 3^{\prime}\right)$ & Reverse primer $\left(5^{\prime} \rightarrow 3^{\prime}\right)$ \\
\hline HP0520 & TGA AGC AAC TCA TGA AAC AAA AA & CCC TGC TCC AAT GAG ACC TA \\
\hline HP0524 (TraG-like protein) & TTG ATT CTG CCA ATC CAT GA & TTC TGC CAT AAT CCC TAC CG \\
\hline HP0527 (VirB10 homologue) & GTT GCG GAT TGT TTG GCT AT & TGC TTG ATG CAA CCT TTC TG \\
\hline HP0528 (VirB9 homologue) & TGC GCT CAA ACA AAT TGA AG & TGG AGT TAT CCT CAG GGC TTT \\
\hline HP0531 & GCA GAT AGG ACA AGC CAA GA & TCC CAC CCA TAC ACA ATC CT \\
\hline HP0534 & TGC CAT TGC AGA GAA TCC TA & TGG GAG CTT AGT GCC ATA CA \\
\hline HP0535 & AAC CAA AGC AGA TCC CAT GT & AAC CAA AGC AGA TCC CAT GT \\
\hline HP0538 & CAG CAT TAT TGC CGA GTG AA & TTG CTC TGC TCT TGC CCT AT \\
\hline HP0539 & CTG AGC AAC AAT GCG GAA TA & AAG CGT CTG TGA AGC AGT GA \\
\hline HP0543 & CAT AAG CGA GGA CAT GCA GA & CCA TGA TCA AAT GCG TGA AG \\
\hline HP0546 (VirB2 homologue) & AGT CCT GCA GAA GGC GTT AC & TAT CCG CTA TGC CTT TGA CC \\
\hline HP0547 (cagA) & TAG CCC TGA ACC CAT TTA CG & TGA TTC CTT GAT CGC CCT AC \\
\hline HP0887 (vacA) & CAC AAC CGT GAT CAT TCC AG & TAT TGG CTT CTT CGG CTT GT \\
\hline
\end{tabular}

\begin{abstract}
Western immunoblotting. Cells were collected from the H. pylorilactobacillus co-cultures by centrifugation. Residual medium was removed from the cell pellet, and the cells were resuspended in sterile water, boiled for $10 \mathrm{~min}$ and stored at $-70{ }^{\circ} \mathrm{C}$. Standard conditions were employed for immunoblotting and SDS-PAGE, in gels containing $10 \%$ acrylamide. Separated proteins were transferred from SDSPAGE gels to nitrocellulose paper by the methanol Tris-glycine system described by Towbin et al. (1979). CagA was detected using a rabbit polyclonal antibody (Santa Cruz Biotech). Bound antibodies were detected using horseradish-peroxidase-coupled goat anti-rabbit immunoglobulin (Dako), with hydrogen peroxide and 4-chloro-1naphthol (Sigma) as chromogenic reagents.
\end{abstract}

Statistical analyses. Data were expressed as the mean \pm SEM unless otherwise stated. Values were compared using a paired $t$-test for parametric data and considered significant if $P$-values were $<0.05$.

\section{RESULTS AND DISCUSSION}

\section{L. salivarius UCC118 inhibits $H$. pylori-induced IL-8 in a dose-dependent manner}

Probiotic bacteria are defined as commensals that, when administered to humans, have an inherent benefit over and above nutrition (Guarner \& Schaafsma, 1998). Some probiotics, including lactobacilli, have previously been shown to decrease inflammatory markers in $H$. pylori infection models both in vitro and in vivo (Johnson-Henry et al., 2004; Tamura et al., 2006). We studied L. salivarius strain UCC118 for this property in vitro because this is a well-characterized strain (Claesson et al., 2006) which has also been demonstrated to have anti-infective ability in murine and porcine models (Casey et al., 2007; Corr et al., 2007). Furthermore, this strain has previously been shown to downregulate IL-8 expression in intestinal epithelial cells (HT29) at baseline, and to suppress IL-8 production triggered by Salmonella (O'Hara et al., 2006). Having previously established that $L$. salivarius UCC118 does not inhibit growth of $H$. pylori (Ryan et al., 2008a), we now proceeded to investigate whether this strain could inhibit H. pylori-induced IL-8 secretion by AGS gastric epithelial cells. AGS cells were pre-treated with an m.o.i. of either $10: 1,50: 1$ or $100: 1$ cells of UCC118 and incubated for $2 \mathrm{~h}$. H. pylori was then added at the same concentrations and cells were co-incubated for a further $4 \mathrm{~h}$. IL- 8 secretion by AGS cells decreased in a dose-dependent manner (Fig. 1a); however, this decrease was only significant at the highest concentrations of UCC118 (m.o.i. 100:1). m.o.i. values of $50: 1 \mathrm{H}$. pylori to AGS cells and 100:1 UCC118 to AGS cells were used in all subsequent experiments.

To further investigate whether this phenomenon was specific to induction by $H$. pylori, we treated AGS cells with TNF- $\alpha$, which also induces gastric epithelial cells to secrete IL-8. Addition of $5 \mathrm{ng}$ TNF- $\alpha \mathrm{ml}^{-1}$ induced significant IL-8 secretion by AGS cells but the presence of UCC118 even up to an m.o.i. of 100:1 did not have any effect on cytokine release (Fig. 1b).

We repeated these initial experiments using a different strain of L. salivarius, UCC119. Unlike UCC118, this strain had previously been shown to inhibit growth of $H$. pylori (Ryan et al., 2008a). Exposure of AGS cells to UCC119 caused a significantly greater reduction in IL-8 secretion in the presence of $H$. pylori than the decrease caused by UCC118 (Fig. 1c).

The reduction in $H$. pylori-stimulated IL-8 production levels in AGS cells was statistically significant only with the highest numbers of lactobacillus cells tested. However, we would argue that this does not necessarily prove that clinically significant levels of reduction in inflammation are unachievable by naturally present or artificially introduced lactobacillus cells. The data we present here may explain some of the previous successful $H$. pylori-probiotic in vivo trials (Franceschi et al., 2007; Lesbros-Pantoflickova et al., 2007). A more modest reduction in inflammation caused by lactobacilli in vivo could be clinically significant in the case of chronic inflammation - assuming that lactobacilli with relevant properties could persist in the stomach. Recent work suggests that this is the case (Bik et al., 2006; Roos et al., 2005; Ryan et al., 2008b). 

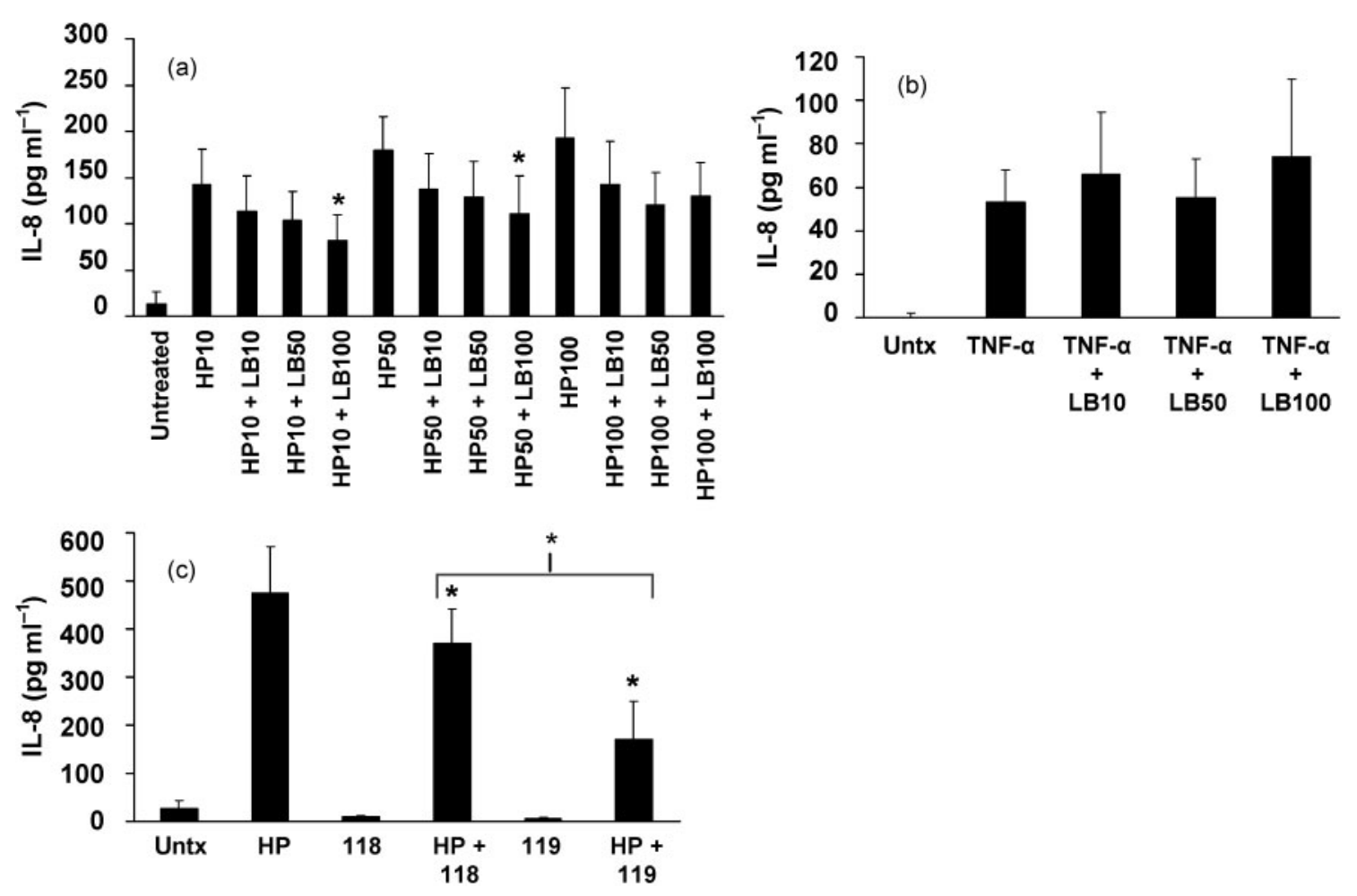

Fig. 1. Lactobacilli inhibit $H$. pylori-induced IL-8 secretion by AGS gastric epithelial cells. (a) L. salivarius UCC118 downregulates $H$. pylori-induced IL-8 secretion by AGS cells in a dose-dependent manner. (b) UCC118 does not inhibit TNF- $\alpha$-induced IL- 8 secretion by AGS cells. (c) UCC118 and UCC119 alone do not induce IL- 8 secretion and UCC119 downregulates $H$. pylori-induced IL-8 secretion by AGS cells more than UCC118. Data shown are from at least three independent experiments carried out in duplicate. ${ }^{*}, P$-value $<0.05$ compared to AGS cells treated with $H$. pylori alone. Untx, untreated.

\section{Lactobacilli modulate the secretion of CCL20 and CXCL10}

We assayed the supernatants from the co-culture assay for five additional chemokines using ELISA and CBA. CCL20 is a chemoattractant for immature dendritic cells, $T$ cells and $B$ cells (Schutyser et al., 2003). It has been shown previously that $H$. pylori induces CCL20 secretion by gastric epithelial cells (Wu et al., 2007). In our hands, $H$. pylori and both $L$. salivarius strains alone induced AGS cells to secrete a small amount of CCL20, but $H$. pylori together with $L$. salivarius UCC118 induced a significant increase in CCL20 secretion compared with either strain alone (Fig. 2a). Conversely, $L$. salivarius UCC119 together with $H$. pylori completely abolished CCL20 secretion by AGS cells (Fig. 2a). L. salivarius UCC118, L. salivarius UCC119 and H. pylori did not induce expression of the chemokines CCL5, CXCL9, CXCL10 or CCL2 (data not shown). However, a combination of $H$. pylori and either L. salivarius strain induced a significant increase in CXCL10 secretion by AGS cells (Fig. 2b). CXCL10 is primarily a chemoattractant for monocytes and T cells (Dufour et al., 2002).

$\mathrm{NF}-\kappa \mathrm{B}$ is a key mediator in the transcription of CCL20 and CXCL10 (Neville et al., 1997; Tomimori et al., 2007).
Although very little is known about the signalling pathways involved in inducing transcription of the genes that encode these chemokines, it is clear from the present data that the pathways involved differ from the well-described IL-8 NF$\kappa \mathrm{B}$ signal transduction pathway as both lactobacilli on their own secreted CCL20 and CXCL10 but not IL-8.

\section{Anti-inflammatory activity of $L$. salivarius UCC118 is not dependent on adhesion, bacteriocin production or cell viability}

We carried out a number of experiments to investigate how L. salivarius UCC118 might inhibit $H$. pylori-induced IL-8 secretion. We first used two previously characterized mutant strains of L. salivarius UCC118 in our co-culture assay. One mutant, which is deficient in the sortase enzyme, has reduced adhesion to intestinal epithelial cells (van Pijkeren et al., 2006). We first confirmed that this mutant strain similarly had a significant reduction in adhesion to gastric epithelial cells (Fig. 3a). The second mutant does not produce a functional Abp118 bacteriocin and cannot inhibit growth of Listeria monocytogenes (Corr et al., 2007). Both mutant strains of UCC118 inhibited $H$. pylori-induced IL-8, and there was no difference between 

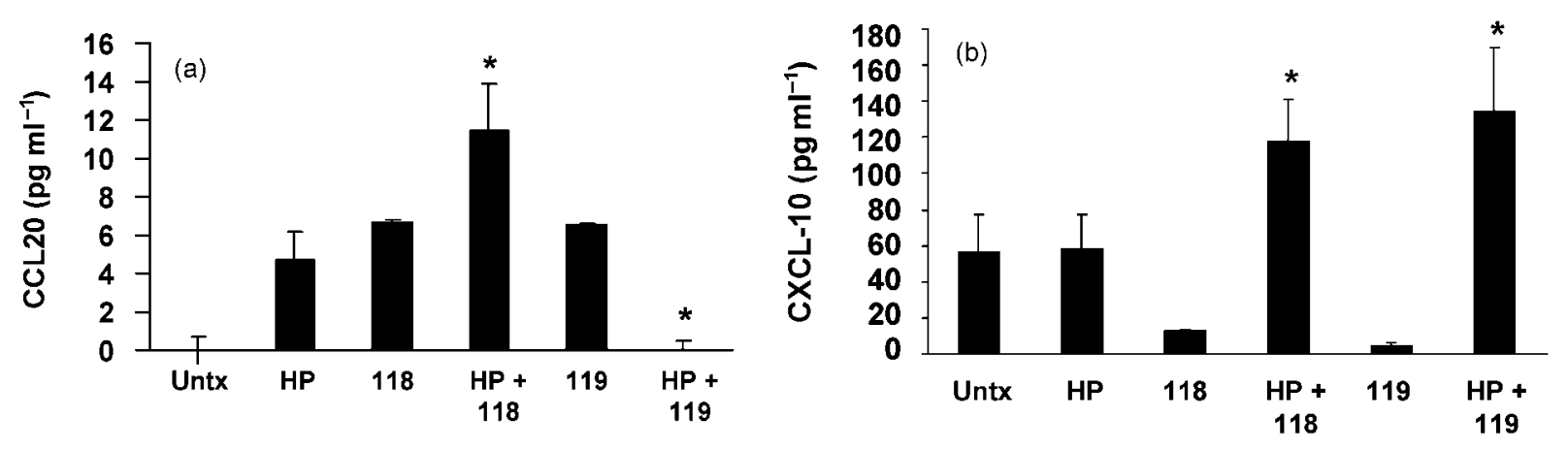

Fig. 2. L. salivarius UCC118 and UCC119 differentially modulate the secretion of other chemokines by AGS cells. (a) UCC118 significantly increases CCL20 secretion by AGS cells in response to $H$. pylori. UCC119 significantly decreases CCL20 secretion by AGS cells in response to H. pylori. (b) Both UCC118 and UCC119 significantly increase CXCL10 secretion by AGS cells in response to $H$. pylori infection. Data shown are from three independent experiments carried out in duplicate. ${ }^{*}, P$-value $<0.05$ compared to AGS cells treated with $H$. pylori alone.

the amount of inhibition observed with either strain compared to wild-type UCC118 (Fig. 3b). This indicates that the anti-inflammatory effect of UCC118 was not due to binding of UCC118 cells to AGS cells, nor was it mediated by a direct antibacterial activity of the UCC118 bacteriocin.

Because we had previously observed that live, viable cells were required for growth inhibition of $H$. pylori (Ryan et al., 2008a), we next tested to see whether the anti-inflammatory properties of UCC118 also required the presence of whole, live and metabolically active cells. There was no difference between the abilities of live UCC118 cells and UCC118 cells killed by UV treatment for $15 \mathrm{~min}$ to diminish H. pylori-induced IL-8 (Fig. 3c). Thus killed UCC118 cells retained the same anti-inflammatory properties.
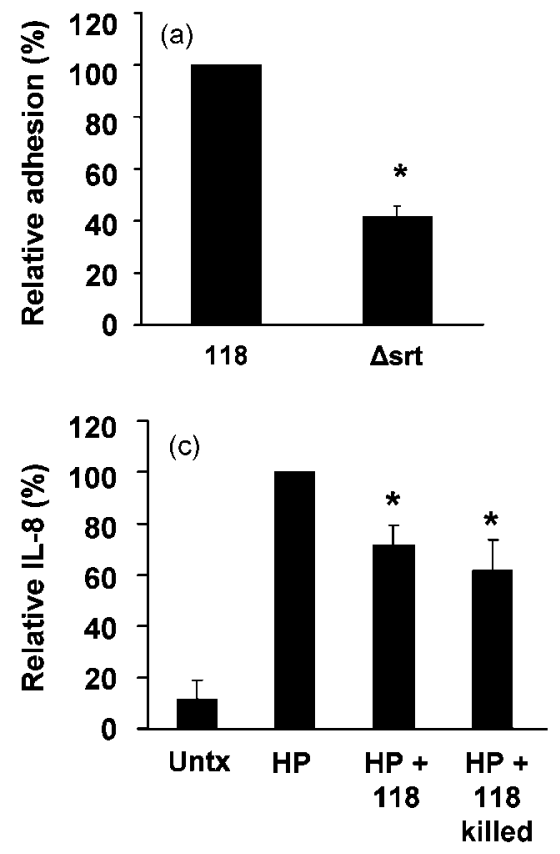
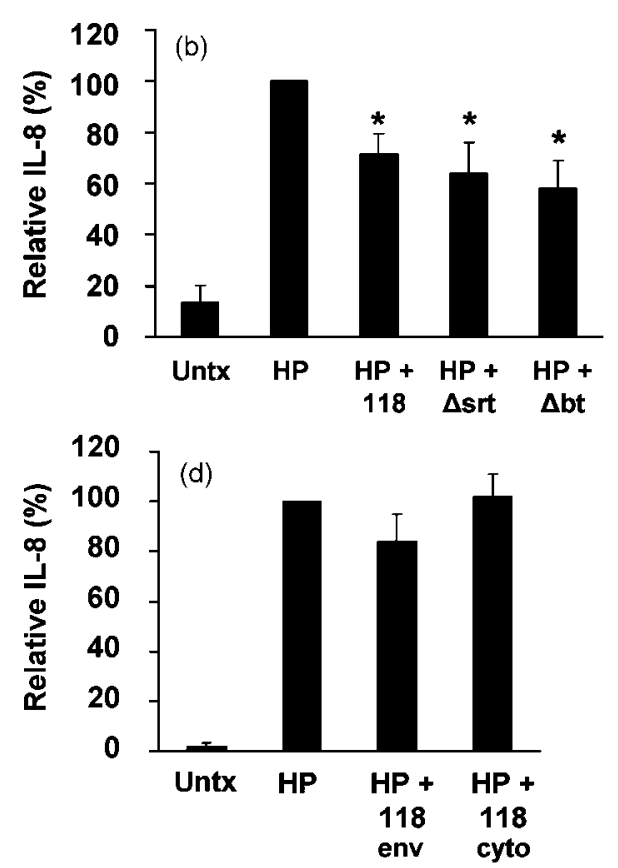

Fig. 3. Anti-inflammatory activity of $L$. salivarius $U C C 118$ is not dependent on adhesion, bacteriocin production or cell viability. (a) A UCC118 sortase mutant has reduced adhesion to AGS cells. (b) $H$. pylori-induced IL-8 secretion is downregulated equally by UCC118 wild-type cells, an adhesion mutant and a bacteriocin-deficient mutant. (c) $H$. pylori-induced IL-8 secretion is downregulated equally by wild-type live and UV-killed cells. (d) Cytoplasmic and envelope fractions of UCC118 do not downregulate $H$. pylori-induced IL-8. Data shown are from at least three independent experiments carried out in duplicate. *, $P$-value $<0.05$ compared to wild-type cells (a) or AGS cells treated with $H$. pylori alone (b, c, d). 
To investigate whether this anti-inflammatory activity of UCC118 could be localized to either the envelope or cytoplasm, fractions of the bacterium were prepared with an equivalent number of cells. Neither the cytoplasmic fraction nor the envelope fraction retained any statistically significant anti-IL-8 activity (Fig. 3d), suggesting that intact cells, either alive or killed, were required.

It is well established that dead $H$. pylori cells do not induce gastric epithelial cells to secrete significant amounts of IL-8 (Aihara et al., 1997; Sharma et al., 1995). As we have previously shown that UCC118 does not have any in vitro antimicrobial activity against $H$. pylori (Ryan et al., 2008a), and a bacteriocin-deficient UCC118 isogenic mutant had the same anti-inflammatory cytokine phenotype as the wild-type, this indicates that the decrease in IL-8 observed upon exposure to lactobacilli was not simply due to a decrease in $H$. pylori numbers. It is worth noting that a previous study showing an anti-IL-8 effect of Lactobacillus gasseri in a similar $H$. pylori infection model did not control for the fact that if the probiotic can kill or retard growth of $H$. pylori, this will in turn lead to less activation of immune responses to the organism (Tamura et al., 2006).

\section{Acid inhibits IL-8 secretion by AGS cells}

Live UCC119 cells inhibited $H$. pylori-induced IL-8 secretion by AGS cells to a greater degree than UCC118
(Fig. 1c). We tested whether this greater inhibitory activity was also present in UV-killed UCC119 cells. Although UVkilled UCC119 cells still inhibited H. pylori-induced IL-8, the decrease observed was significantly less than that seen for live UCC119 cells (Fig. 3c and Fig. 4a). The levels of IL8 that we measured using UV-killed UCC119 cells were not significantly different to those seen with live or UV-killed UCC118 cells, suggesting that the source of the effect was possibly the same in both cases. It also suggested that UCC119 had a second viability-dependent mechanism for modulating IL-8 production. We had observed that strain UCC119 produced much more acid in culture than UCC118, so we hypothesized that this may be responsible for the IL-8 reduction difference observed between the strains. We grew UCC119 overnight in Ham's F-12 medium, centrifuged the culture and used the filtered cell-free supernatant instead of cells in the co-culture assay. This UCC119 spent medium (pH 4) completely abolished IL-8 secretion by AGS cells infected with $H$. pylori (Fig. 4b). In contrast, UCC119 spent medium adjusted to $\mathrm{pH} 7$ (with filtered sodium hydroxide) did not have any effect on IL-8 secretion (Fig. 4b). We tested AGS cell viability using trypan blue staining and did not observe any differences in viability comparing cells treated with either UCC119 spent media or H. pylori alone (data not shown). Furthermore, although we observed a slight decrease in $H$. pylori viability at $\mathrm{pH} 3$, the viability of $H$. pylori cells was not diminished at $\mathrm{pH} 4$.
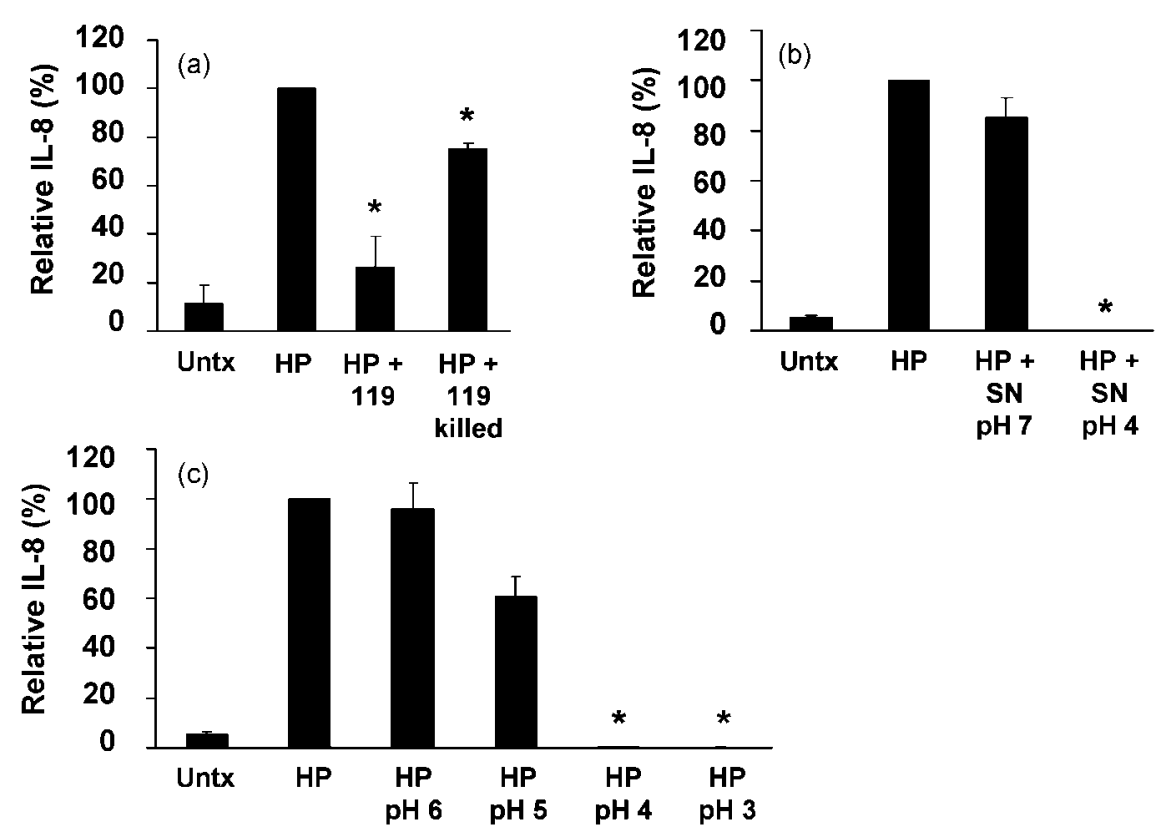

Fig. 4. Inhibition of $H$. pylori-induced IL-8 secretion by L. salivarius UCC119 is partly due to the production of acid. (a) UV-killed UCC119 cells do not inhibit $H$. pylori-induced IL-8 as well as live cells. (b) UCC119 cell supernatant inhibits H. pylori-induced IL-8; UCC119 cell supernatant adjusted to $\mathrm{pH} 7$ does not. (c) In the absence of lactobacilli, acid alone can inhibit $H$. pylori-induced IL-8 secretion by AGS cells. Data shown are from at least three independent experiments carried out in duplicate. *, $P$-value $<0.05$ compared to AGS cells treated with $H$. pylori alone. SN, supernatant. 
We next assessed whether adjusting the $\mathrm{pH}$ of the tissue culture media alone would have any effect on $H$. pyloriinduced IL-8 in the absence of UCC119 cells or media (Fig. 4c). AGS cells did not produce any IL-8 in response to $H$. pylori infection when the medium was adjusted to $\mathrm{pH} 4$ or $\mathrm{pH}$ 3. H. pylori-induced IL-8 decreased at $\mathrm{pH} 5$ although this was not significant, and there was no reduction at $\mathrm{pH}$ 6. Thus lowering the $\mathrm{pH}$ in the vicinity of gastric epithelial cells by lactobacillus fermentation activity could contribute to a reduction in inflammation.

A previous study by Choi et al. (2007) has shown, contradictory to our own findings, that IL-8 secretion by AGS cells in response to $H$. pylori infection is in fact enhanced at lower $\mathrm{pH}$. One explanation for this difference might be due to the different properties of the acids used to adjust the $\mathrm{pH}$ of the media. The previous study used hydrochloric acid whereas we used lactic acid. Both this study and that of Choi et al. (2007) were performed in the absence of serum.

\section{L. salivarius UCC118 alters expression and functionality of the Cag type IV secretion system}

It is well established that proteins of the Cag PAI are largely responsible for inducing IL-8 secretion by gastric epithelial cells, both in vivo and in vitro (Brandt et al., 2005; Fischer et al., 2001; Sharma et al., 1995). We therefore carried out qRT-PCR on 12 genes of the Cag PAI from $H$. pylori cells taken from the co-culture system to test for changes in the expression of these genes in the presence of L. salivarius. Strain UCC118 was used, since strain UCC119 has direct anti-H. pylori activity that would have confounded the assay (Ryan et al., 2008a). cag genes spanning the entire PAI were chosen. When it appeared likely from bioinformatic analysis that a group of genes were co-transcribed, we endeavoured to include at least one gene from each transcriptional unit. Of the 12 genes tested, eight were downregulated in the presence of UCC118 cells (Fig. 5), and of these, five were downregulated more than twofold (HP0520, HP0527, HP0534, HP0538 and HP0539). One gene, HP0528, was upregulated and there was no change in the expression of three genes. Expression of cagA (HP0547) was unchanged in the presence of UCC118.

We used Western immunoblotting to examine cellular levels of CagA protein in $H$. pylori in either the presence or absence of L. salivarius UCC118. Higher levels of CagA were observed in $H$. pylori cells in the presence of $L$. salivarius UCC18, indicating that the Cag secretion system was disrupted (Fig. 6). There was also an increase in the amount of the $40 \mathrm{kDa}$ processed form of CagA (Moese et al., 2001) in the presence of UCC118 (marked with an arrow). Cellular levels of the constitutively expressed protein Lpp20 (O'Toole et al., 1995) were unchanged by exposure of $H$. pylori cells to $L$. salivarius (Fig. 6). We were unable to detect CagA protein in the cell supernatants (data not shown). This is not surprising since CagA is only translocated in significant amounts into host cells via the Cag secretion needle at later time points $(>12 \mathrm{~h}$ ) (Brandt et al., 2005). Prior to this, Cag-mediated IL-8 induction is primarily through a peptidoglycan-Nod1-mediated pathway (Viala et al., 2004). Our data, however, suggest that UCC118 may affect the virulence of $H$. pylori by decreasing the functionality of the secretion system at early time points.

\section{Other lactobacilli modulate cag expression}

To investigate whether the ability to downregulate cag genes was specific to L. salivarius UCC118, we tested the expression of three cag genes in the presence of four other lactobacilli (Fig. 7). These genes were chosen because they had previously been shown to be essential for maximal IL-8 induction (Fischer et al., 2001) and also because they were downregulated in the presence of UCC118 (Fig. 5). Only

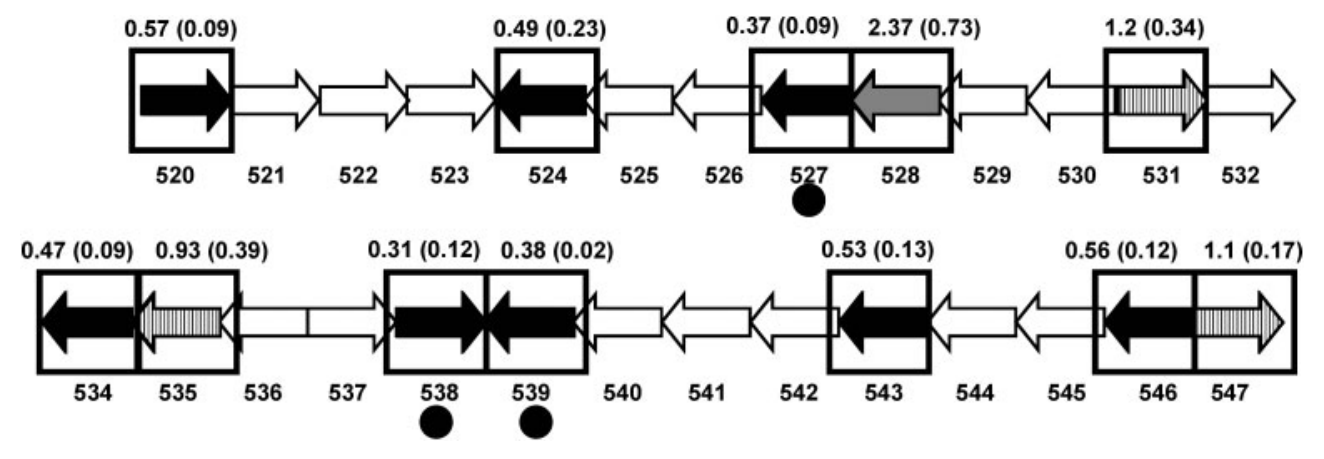

Fig. 5. The presence of $L$. salivarius UCC118 downregulates expression of genes of the $H$. pylori cag pathogenicity island. Schematic showing the gene orientation of the $H$. pylori Cag PAI (TIGR gene annotations are shown below the gene). Expression of boxed genes was measured in the presence or absence of $L$. salivarius UCC118. Genes in black were downregulated in the presence of UCC118, those in stripes showed no change, and those in grey were upregulated. Fold change in gene expression is shown above the gene (standard error of the mean is given in parentheses). Data shown are from three independent experiments. Genes marked with a dot are known to be essential for maximum IL-8 induction (see text). 


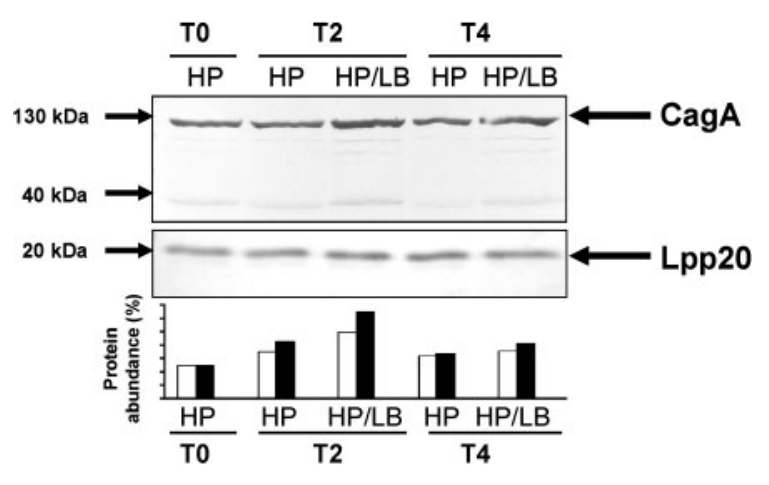

Fig. 6. CagA protein accumulates in $H$. pylori cells cultured in the presence of $L$. salivarius UCC118 after $2 \mathrm{~h}$ and $4 \mathrm{~h}$. Lanes: $1, H$. pylori alone; $2, H$. pylori alone $2 \mathrm{~h} ; 3, H$. pylori and $L$. salivarius UCC118, $2 \mathrm{~h} ; 4, H$. pylori alone $4 \mathrm{~h} ; 5, H$. pylori and $L$. salivarius UCC118 $4 \mathrm{~h}$. The blot shown is representative of three independent experiments. A densitometric analysis of the blot is also shown for comparison purposes. Black bars represent abundance of the $40 \mathrm{kDa}$ form of CagA while the white bars represent abundance of the $120 \mathrm{kDa}$ form, both normalized to abundance of Lpp20.

gene HP0539 in the presence of L. sakei, and HP0527 in the presence of L. acidophilus, were downregulated to statistically significant levels. There was no change in expression of most genes, with the exception of HP0527, which was upregulated in the case of $3 / 4$ lactobacilli. It is interesting to note that $L$. salivarius UCC118 downregulated the expression of the cag genes examined more consistently than the other species studied.

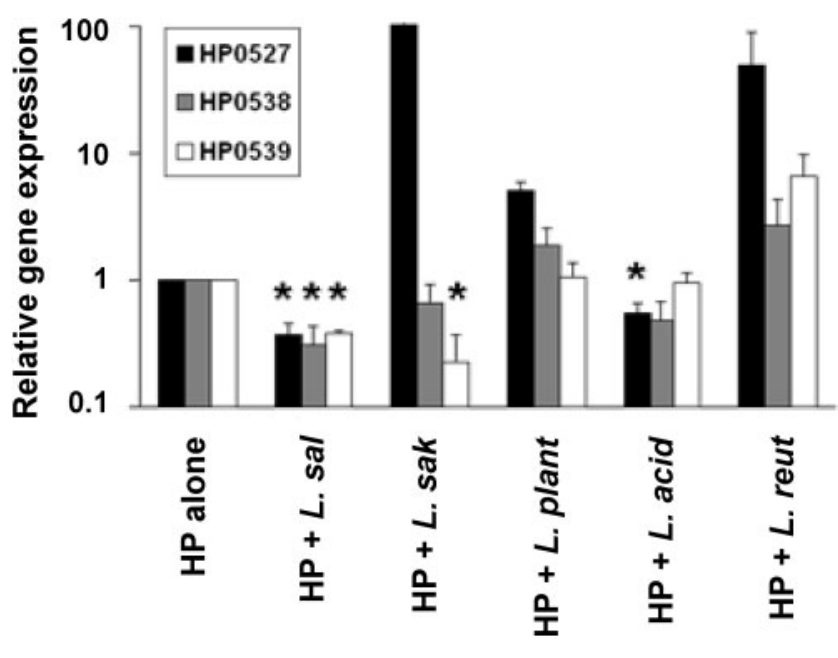

Fig. 7. Comparison of expression of three essential cag genes in $H$. pylori cells cultured with L. salivarius UCC118 (L. sal) and four other lactobacilli as described in Methods: L. sakei (L. sak); $L$. plantarum (L. plant); L. acidophilus (L. acid); L. reuteri (L. reut).
Interestingly, recent studies on $E$. coli have shown that probiotics can downregulate virulence genes of the locus of enterocyte effacement (LEE) PAI (Jelcic et al., 2008; Medellin-Pena et al., 2007), possibly through a quorum sensing-mediated process (Jelcic et al., 2008). In the present study, since whole UCC118 cells either live or UV-killed repressed $H$. pylori-induced IL- 8 but envelope or cytoplasmic fractions did not, it is possible that we are observing a similar phenomenon. Furthermore, envelope fractions of UCC118 did not decrease expression of any of the $12 \mathrm{cag}$ genes examined (data not shown). Moreover strain UCC118 was not able to decrease TNF- $\alpha$-induced IL-8, suggesting that the bacteria were not a general antiinflammatory stimulus to AGS cells. This is consistent with the evidence presented here that reduction in cag gene transcription and intracellular CagA accumulation is the basis for the anti-inflammatory effect seen with $L$. salivarius UCC118.

\section{Concluding remarks}

Direct inhibition of $H$. pylori by L. salivarius is strainspecific (Ryan et al., 2008a) and thus a combination of variable lactobacillus populations in the stomach, and variable lactobacillus phenotypes (Fig. 8) - anti-H. pylori activity and modulation of inflammatory cytokine pro-

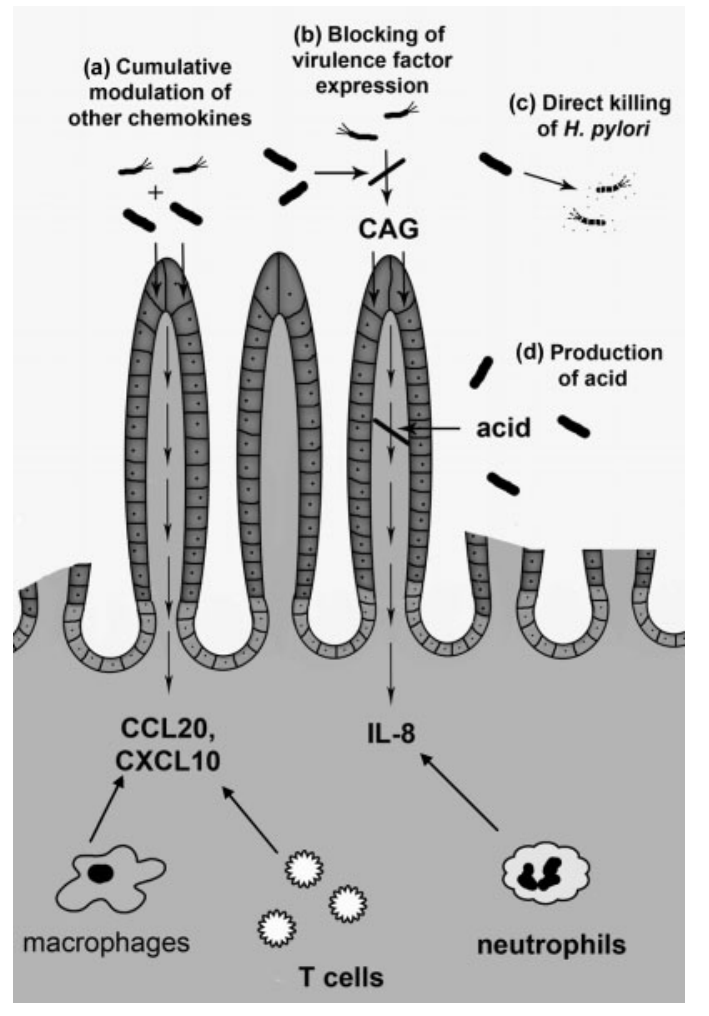

Fig. 8. Schematic diagram showing how L. salivarius might modulate the immune response of gastric epithelial cells to $H$. pylori by a number of different mechanisms. 
duction - could add another dimension to the recognized dependence of clinical severity and outcome of $H$. pylori infection on $H$. pylori genotype and host genotype (reviewed by Gillen \& McColl, 2005). As illustrated in Fig. 8, enhanced CCL20 and CXCL10 combined with decreased IL-8 secretion during $H$. pylori infection would skew the host immune system away from strongly neutrophil-mediated chronic inflammation (Robinson et al., 2007) and towards a more cell-mediated immunity by increasing numbers of macrophages, $\mathrm{B}$ cells and $\mathrm{T}$ cells (Neville et al., 1997; Schutyser et al., 2003).

This work describes a novel mechanism for how probiotics can decrease inflammation during infection with the pathogen $H$. pylori and this could explain why some probiotic bacteria have been shown to have a positive effect on $H$. pylori-associated inflammation without clearing the infection. Preclinical studies have already shown that vaccines can clear Helicobacter infection, indicating that it may be possible to successfully exploit the host immune system to alter the outcome of infection (Velin et al., 2005; Weltzin et al., 1997). In addition to acid production, our data indicate a second mechanism for inhibition of IL-8 production by AGS cells that requires intact whole lactobacillus cells, but not necessarily live cells. Arguing for such a specific mechanism is the fact that several other lactobacillus species tested failed to impact on cag gene transcription, even though some, like L. acidophilus, also bind to human epithelial cells in vitro (Buck et al., 2005). A candidate mechanism could be energy-dependent secretion of a preformed metabolite or protein that inhibits cag gene transcription. This could be a direct lactobacillus $-H$. pylori interaction effect, or driven by feedback from altered interaction of $H$. pylori cells with the AGS cells. Experiments are under way to explore these possibilities.

\section{ACKNOWLEDGEMENTS}

This study was supported by grants from the Irish Research Council for Science Engineering and Technology (to K. A. R.) and the Science Foundation Ireland CSET program to the Alimentary Pharmabiotic Centre (to P.W.O'T.).

\section{REFERENCES}

Aihara, M., Tsuchimoto, D., Takizawa, H., Azuma, A., Wakebe, H., Ohmoto, Y., Imagawa, K., Kikuchi, M., Mukaida, N. \& Matsushima, K. (1997). Mechanisms involved in Helicobacter pylori-induced interleukin- 8 production by a gastric cancer cell line, MKN45. Infect Immun 65, 3218-3224.

Bik, E. M., Eckburg, P. B., Gill, S. R., Nelson, K. E., Purdom, E. A., Francois, F., Perez-Perez, G., Blaser, M. J. \& Relman, D. A. (2006). Molecular analysis of the bacterial microbiota in the human stomach. Proc Natl Acad Sci U S A 103, 732-737.

Bourzac, K. M., Botham, C. M. \& Guillemin, K. (2007). Helicobacter pylori CagA induces AGS cell elongation through a cell retraction defect that is independent of Cdc42, Rac1, and Arp2/3. Infect Immun $75,1203-1213$.
Brandt, S., Kwok, T., Hartig, R., Konig, W. \& Backert, S. (2005). NFkappaB activation and potentiation of proinflammatory responses by the Helicobacter pylori CagA protein. Proc Natl Acad Sci U S A 102, 9300-9305.

Buck, B. L., Altermann, E., Svingerud, T. \& Klaenhammer, T. R. (2005). Functional analysis of putative adhesion factors in Lactobacillus acidophilus NCFM. Appl Environ Microbiol 71, 83448351.

Casey, P. G., Gardiner, G. E., Casey, G., Bradshaw, B., Lawlor, P. G., Lynch, P. B., Leonard, F. C., Stanton, C., Ross, R. P. \& other authors (2007). A five-strain probiotic combination reduces pathogen shedding and alleviates disease signs in pigs challenged with Salmonella enterica serovar Typhimurium. Appl Environ Microbiol 73, 1858-1863.

Choi, I. J., Fujimoto, S., Yamauchi, K., Graham, D. Y. \& Yamaoka, Y. (2007). Helicobacter pylori environmental interactions: effect of acidic conditions on $H$. pylori-induced gastric mucosal interleukin-8 production. Cell Microbiol 9, 2457-2469.

Claesson, M. J., Li, Y., Leahy, S., Canchaya, C., van Pijkeren, J. P., Cerdeño-Tárraga, A. M., Parkhill, J., Flynn, S., O'Sullivan, G. C. \& other authors (2006). Multireplicon genome architecture of Lactobacillus salivarius. Proc Natl Acad Sci U S A 103, 6718-6723.

Corr, S. C., Li, Y., Riedel, C. U., O'Toole, P. W., Hill, C. \& Gahan, C. G. (2007). Bacteriocin production as a mechanism for the antiinfective activity of Lactobacillus salivarius UCC118. Proc Natl Acad Sci U S A 104, 7617-7621.

Corsetti, A., Settanni, L. \& Van Sinderen, D. (2004). Characterization of bacteriocin-like inhibitory substances (BLIS) from sourdough lactic acid bacteria and evaluation of their in vitro and in situ activity. J Appl Microbiol 96, 521-534.

De Vries, A. C., Van Driel, H. F., Richardus, J. H., Ouwendijk, M., Van Vuuren, A. J., De Man, R. A. \& Kuipers, E. J. (2008). Migrant communities constitute a possible target population for primary prevention of Helicobacter pylori-related complications in low incidence countries. Scand J Gastroenterol 43, 403-409.

Dufour, J. H., Dziejman, M., Liu, M. T., Leung, J. H., Lane, T. E. \& Luster, A. D. (2002). IFN-gamma-inducible protein 10 (IP-10; CXCL10)-deficient mice reveal a role for IP-10 in effector T cell generation and trafficking. J Immunol 168, 3195-3204.

Dunne, C., O’Mahony, L., Murphy, L., Thornton, G., Morrissey, D., O'Halloran, S., Feeney, M., Flynn, S., Fitzgerald, G. \& other authors (2001). In vitro selection criteria for probiotic bacteria of human origin: correlation with in vivo findings. Am J Clin Nutr 73, 386S$392 S$.

Fischer, W., Puls, J., Buhrdorf, R., Gebert, B., Odenbreit, S. \& Haas, R. (2001). Systematic mutagenesis of the Helicobacter pylori cag pathogenicity island: essential genes for CagA translocation in host cells and induction of interleukin-8. Mol Microbiol 42, 1337-1348.

Franceschi, F., Cazzato, A., Nista, E. C., Scarpellini, E., Roccarina, D., Gigante, G., Gasbarrini, G. \& Gasbarrini, A. (2007). Role of probiotics in patients with Helicobacter pylori infection. Helicobacter 12 (Suppl. 2), 59-63.

Gillen, D. \& McColl, K. E. (2005). Gastroduodenal disease, Helicobacter pylori, and genetic polymorphisms. Clin Gastroenterol Hepatol 3, 1180-1186.

Graham, D. Y. \& Shiotani, A. (2008). New concepts of resistance in the treatment of Helicobacter pylori infections. Nat Clin Pract Gastroenterol Hepatol 5, 321-331.

Guarner, F. \& Schaafsma, G. J. (1998). Probiotics. Int J Food Microbiol 39, 237-238.

Higashi, H., Tsutsumi, R., Fujita, A., Yamazaki, S., Asaka, M., Azuma, T. \& Hatakeyama, M. (2002). Biological activity of the Helicobacter 
pylori virulence factor CagA is determined by variation in the tyrosine phosphorylation sites. Proc Natl Acad Sci U S A 99, 14428-14433.

Jelcic, I., Hufner, E., Schmidt, H. \& Hertel, C. (2008). Repression of the LEE-encoded regulator gene transcription of E. coli O157:H7 by culture supernatants of Lactobacillus reuteri is LuxS and strain dependent. Appl Environ Microbiol 74, 3310-3314.

Johnson-Henry, K. C., Mitchell, D. J., Avitzur, Y., Galindo-Mata, E., Jones, N. L. \& Sherman, P. M. (2004). Probiotics reduce bacterial colonization and gastric inflammation in Helicobacter pylori-infected mice. Dig Dis Sci 49, 1095-1102.

Lesbros-Pantoflickova, D., Corthesy-Theulaz, I. \& Blum, A. L. (2007). Helicobacter pylori and probiotics. J Nutr 137, 812S-818S.

Magalhaes Queiroz, D. M. \& Luzza, F. (2006). Epidemiology of Helicobacter pylori infection. Helicobacter 11 (Suppl. 1), 1-5.

Medellin-Pena, M. J., Wang, H., Johnson, R., Anand, S. \& Griffiths, M. W. (2007). Probiotics affect virulence-related gene expression in Escherichia coli O157: H7. Appl Environ Microbiol 73, 4259-4267.

Moese, S., Selbach, M., Zimny-Arndt, U., Jungblut, P. R., Meyer, T. F. \& Backert, S. (2001). Identification of a tyrosine-phosphorylated 35 $\mathrm{kDa}$ carboxy-terminal fragment (p35CagA) of the Helicobacter pylori CagA protein in phagocytic cells: processing or breakage? Proteomics 1, 618-629.

Neville, L. F., Mathiak, G. \& Bagasra, O. (1997). The immunobiology of interferon-gamma inducible protein $10 \mathrm{kD}$ (IP-10): a novel, pleiotropic member of the $\mathrm{C}-\mathrm{X}-\mathrm{C}$ chemokine superfamily. Cytokine Growth Factor Rev 8, 207-219.

O’Hara, A. M., O'Regan, P., Fanning, A., O'Mahony, C., Macsharry, J., Lyons, A., Bienenstock, J., O'Mahony, L. \& Shanahan, F. (2006). Functional modulation of human intestinal epithelial cell responses by Bifidobacterium infantis and Lactobacillus salivarius. Immunology 118, 202-215.

O’Toole, P. W., Janzon, L., Doig, P., Huang, J., Kostrzynska, M. \& Trust, T. J. (1995). The putative neuraminyllactose-binding hemagglutinin HpaA of Helicobacter pylori CCUG 17874 is a lipoprotein. $J$ Bacteriol 177, 6049-6057.

Pena, J. A., Rogers, A. B., Ge, Z., Ng, V., Li, S. Y., Fox, J. G. \& Versalovic, J. (2005). Probiotic Lactobacillus spp. diminish Helicobacter hepaticus-induced inflammatory bowel disease in interleukin-10-deficient mice. Infect Immun 73, 912-920.

Robinson, K., Argent, R. H. \& Atherton, J. C. (2007). The inflammatory and immune response to Helicobacter pylori infection. Best Pract Res Clin Gastroenterol 21, 237-259.

Rokka, S., Myllykangas, S. \& Joutsjoki, V. (2008). Effect of specific colostral antibodies and selected lactobacilli on the adhesion of Helicobacter pylori on AGS cells and the Helicobacter-induced IL-8 production. Scand J Immunol 68, 280-286.

Roos, S., Engstrand, L. \& Jonsson, H. (2005). Lactobacillus gastricus sp. nov., Lactobacillus antri sp. nov., Lactobacillus kalixensis sp. nov. and Lactobacillus ultunensis sp. nov., isolated from human stomach mucosa. Int J Syst Evol Microbiol 55, 77-82.

Ryan, K. A., van Doorn, L. J., Moran, A. P., Glennon, M., Smith, T. \& Maher, M. (2001). Evaluation of clarithromycin resistance and cagA and vacA genotyping of Helicobacter pylori strains from the west of Ireland using line probe assays. J Clin Microbiol 39, 1978-1980.

Ryan, K. A., Daly, P., Li, Y., Hooton, C. \& O'Toole, P. W. (2008a). Strain-specific inhibition of Helicobacter pylori by Lactobacillus salivarius and other lactobacilli. J Antimicrob Chemother 61, 831-834.

Ryan, K. A., Jayaraman, T., Daly, P., Canchaya, C., Curran, S., Fang, F., Quigley, E. \& O'Toole, P. W. (2008b). Isolation of lactobacilli with probiotic properties from the human stomach. Lett Appl Microbiol 47, 269-274.
Schutyser, E., Struyf, S. \& Van Damme, J. (2003). The CC chemokine CCL20 and its receptor CCR6. Cytokine Growth Factor Rev 14, 409426.

Sgouras, D. N., Panayotopoulou, E. G., Martinez-Gonzalez, B., Petraki, K., Michopoulos, S. \& Mentis, A. (2005). Lactobacillus johnsonii Lal attenuates Helicobacter pylori-associated gastritis and reduces levels of proinflammatory chemokines in C57BL/6 mice. Clin Diagn Lab Immunol 12, 1378-1386.

Sharma, S. A., Tummuru, M. K., Miller, G. G. \& Blaser, M. J. (1995). Interleukin-8 response of gastric epithelial cell lines to Helicobacter pylori stimulation in vitro. Infect Immun 63, 1681-1687.

Stein, M., Rappuoli, R. \& Covacci, A. (2000). Tyrosine phosphorylation of the Helicobacter pylori CagA antigen after cag-driven host cell translocation. Proc Natl Acad Sci U S A 97, 1263-1268.

Su, B., Ceponis, P. J. \& Sherman, P. M. (2003). Cytoskeletal rearrangements in gastric epithelial cells in response to Helicobacter pylori infection. J Med Microbiol 52, 861-867.

Tamura, A., Kumai, H., Nakamichi, N., Sugiyama, T., Deguchi, R., Takagi, A. \& Koga, Y. (2006). Suppression of Helicobacter pyloriinduced interleukin- 8 production in vitro and within the gastric mucosa by a live Lactobacillus strain. J Gastroenterol Hepatol 21, 13991406.

Tomimori, K., Uema, E., Teruya, H., Ishikawa, C., Okudaira, T., Senba, M., Yamamoto, K., Matsuyama, T., Kinjo, F. \& other authors (2007). Helicobacter pylori induces CCL20 expression. Infect Immun 75, 5223-5232.

Towbin, H., Staehelin, T. \& Gordon, J. (1979). Electrophoretic transfer of proteins from polyacrylamide gels to nitrocellulose sheets: procedure and some applications. Proc Natl Acad Sci U S A 76, $4350-4354$.

Uemura, N., Okamoto, S., Yamamoto, S., Matsumura, N., Yamaguchi, S., Yamakido, M., Taniyama, K., Sasaki, N. \& Schlemper, R. J. (2001). Helicobacter pylori infection and the development of gastric cancer. $N$ Engl J Med 345, 784-789.

Vakil, N. \& Megraud, F. (2007). Eradication therapy for Helicobacter pylori. Gastroenterology 133, 985-1001.

van Pijkeren, J. P., Canchaya, C., Ryan, K. A., Li, Y., Claesson, M. J., Sheil, B., Steidler, L., O'Mahony, L., Fitzgerald, G. F. \& other authors (2006). Comparative and functional analysis of sortase-dependent proteins in the predicted secretome of Lactobacillus salivarius UCC118. Appl Environ Microbiol 72, 4143-4153.

Velin, D., Bachmann, D., Bouzourene, H. \& Michetti, P. (2005). Mast cells are critical mediators of vaccine-induced Helicobacter clearance in the mouse model. Gastroenterology 129, 142-155.

Viala, J., Chaput, C., Boneca, I. G., Cardona, A., Girardin, S. E., Moran, A. P., Athman, R., Mémet, S., Huerre, M. R. \& other authors (2004). Nod1 responds to peptidoglycan delivered by the Helicobacter pylori cag pathogenicity island. Nat Immunol 5, 1166-1174.

Weltzin, R., Kleanthous, H., Guirakhoo, F., Monath, T. P. \& Lee, C. K. (1997). Novel intranasal immunization techniques for antibody induction and protection of mice against gastric Helicobacter felis infection. Vaccine 15, 370-376.

Wu, Y. Y., Tsai, H. F., Lin, W. C., Hsu, P. I., Shun, C. T., Wu, M. S. \& Hsu, P. N. (2007). Upregulation of CCL20 and recruitment of CCR6+ gastric infiltrating lymphocytes in Helicobacter pylori gastritis. Infect Immun 75, 4357-4363.

Zhou, C., Ma, F. Z., Deng, X. J., Yuan, H. \& Ma, H. S. (2008). Lactobacilli inhibit interleukin-8 production induced by Helicobacter pylori lipopolysaccharide-activated Toll-like receptor 4. World J Gastroenterol 14, 5090-5095. 